\title{
Cultivando o desenho da criança: liberdade, encantamento e transgressão
}

\author{
Cultivating the child's drawing: freedom, enchantment and \\ transgression
}

\section{Cultivar el dibujo infantil: libertad, encanto y transgresión}

\author{
Jocicleia Souza Printes 1 \\ htps://orcid.org/0000-0002-6065-6058 \\ Michelle de Freitas Bissoli² \\ https://orcid.org/0000-0002-2570-4392
}

\begin{abstract}
Resumo: Este texto é fruto de uma pesquisa de doutorado na linha de formação de professores que objetivou compreender como um processo de formação continuada com professoras da pré-escola, a partir da perspectiva da teoria Histórico-Cultural, pode contribuir para que seu trabalho amplie as possibilidades de expressão infantil, especialmente pelo desenho. Observamos como as relações se davam e como o desenho ocupava tempo e espaço no planejamento. Por meio da pesquisa com formação, propusemos um grupo de estudos para discutirmos sobre a necessidade da arte, formação estética, imaginação e criação. As experiências propostas pelas professoras passaram a pensar o desenho numa combinação do corpo em movimento, superfícies e marcadores. O desenho ganhou centralidade no planejamento e ressignificou o fazer, antes preocupado apenas com o resultado. Processo e produto passaram a dialogar e o resultado foi um conjunto de experiências de fruição e liberdade, valorizando o desenho como expressão.
\end{abstract}

Palavras-chave: Formação de professores. Arte. Desenho.

\begin{abstract}
This text is the result of a doctoral research in the field of teacher education that aimed to understand how a process of continuing education with kindergarten's teachers, from the perspective of Historical-Cultural theory, can contribute to their work to expand the possibilities of childish expression, especially by drawing. We observed how the relationships got together and how the drawing spend time and space in planning. Through research with formation, we proposed a group's studies to discuss the need for art, aesthetic formation, imagination and creation. The experiences proposed by the teachers started to think the drawing as a combination of the body in motion, surfaces and markers. Drawing gained centrality in planning and gave new meaning to doing, before it was only concerned with the result. Process and product started to dialogue and the result was experiences of enjoyment and freedom, valuing drawing as an expression.
\end{abstract}

\footnotetext{
' Doutora em Educação. Professora Assistente do Centro de Estudos Superiores de Tabatinga. Universidade do Estado do Amazonas. E-mail: cleiaprintes@gmail.com

${ }^{2}$ Doutora em Educação. Professora Associado IV da Faculdade de Educação. Professora no Programa de PósGraduação em Educação. Universidade Federal do Amazonas. E-mail: mibissoli@yahoo.com.b
}

Olhar de professor, Ponta Grossa, v. 24, p. I-24, e-17664.07I, 2021.

Disponível em <https://revistas2.uepg.br/index.php/olhardeprofessor> 
Keywords: Teacher training. Art. Drawing.

Resumen: Este texto es el resultado de una investigación de doctorado en la línea de formación docente que tuvo como objetivo comprender cómo se desarrolla un proceso de educación continuada con profesores de preescolar, desde la perspectiva de la teoría Histórico-Cultural, puede contribuir a su obra ampliando las posibilidades de expresión de los niños, especialmente a través del dibujo. Observamos cómo se desarrollaban las relaciones y cómo el dibujo ocupaba tiempo y espacio en la planificación. Mediante de la investigación con formación, propusimos un grupo de estudio para discutir la necesidad del arte, la formación estética, la imaginación y la creación. Las experiencias propuestas por los profesores comenzaron a pensar en el dibujo como una combinación del cuerpo en movimiento, superficies y marcadores. El dibujo ganó un lugar central en la planificación y dio un nuevo significado a la creación, que antes solo se preocupaba por el resultado. Proceso y producto comenzaron a dialogar y el resultado fue un conjunto de experiencias de fructificación y libertad, valorando el dibujo como expresión.

Palabras-clave: Formación de profesores. Arte. Dibujo.

\section{Introdução}

Em nosso percurso de observação e participação no cotidiano de um Centro Municipal de Educação Infantil, analisamos as relações que foram tecidas entre as propostas de discussão conceitual e a observação do trabalho com desenho desenvolvido pelas professoras, por intermédio do planejamento das atividades e propostas apresentadas às crianças. Defendemos a tese de que compreender o desenho a partir da perspectiva da teoria Histórico-Cultural, em um processo de formação continuada, permite às professoras ampliar e enriquecer $\circ$ desenvolvimento $e$ as possibilidades de expressão das crianças à medida que são ampliadas as suas referências teóricopráticas a respeito dessa forma de expressão.

Cabe destacar que, sob essa perspectiva teórico-conceitual, pensar a atividade do desenho na pré-escola se aproxima da necessidade de buscar compreender em que realidade concreta estão situados a escola, o trabalho e a formação das professoras, além das crianças, do lugar ocupado pela atividade de desenhar e do valor atribuído a ela nas escolas e na sociedade em que vivemos, compreendendo, como assegura Pinto (1969), o compromisso do cientista com a transformação da realidade.

Nessa perspectiva, nos acercamos da pesquisa com formação (GOMES, 2006; LONGAREZI; SILVA, 20I3; PERRELI et. al, 20I3), para construirmos uma relação entre encontros no grupo de estudo e as propostas desenvolvidas diariamente com as crianças. Desejávamos desenvolver um processo coletivo e autoral, no qual os sujeitos também produzissem os dados da pesquisa. As experiências vivenciadas foram, aos poucos, promovendo estranhamentos e percepções. À medida que as professoras se sentiam desafiadas e acolhidas, as propostas iam sendo partilhadas. As ideias propostas e experimentadas por um grupo circulavam pelas outras turmas. Ideias dos anos anteriores voltavam à cena, ressignificadas. Outras sugestões e materiais foram surgindo para além daqueles 
trazidos pela pesquisa. Mas isso se deu em um processo que demandou tempo, reflexão, escutas, olhares, percepções.

Algumas ideias foram logo abraçadas, outras olhadas com desconfiança, o que é normal em todo processo de mudança. Admitamos que não é fácil sair do lugar comum de crianças e salas limpas, materiais e propostas controláveis, que deixam meninos e meninas sentados por longos períodos. Além disso, tarefas de escrever letras e números, repetir o nome completo, marcar o que está em cima, embaixo, colar grãos nos objetos da esquerda e da direita e cobrir pontilhados etc., na compreensão de muitos adultos, estão preparando as crianças para o ensino fundamental, o que, de certa forma, reduz a pressão por aquilo que esperam da educação infantil, quando muitas tarefas no papel são entregues às famílias.

Nas escolas da infância, ainda há questionamentos que querem saber como "ligar" a brincadeira à tarefa que a criança precisa fazer para aprender determinado "conteúdo", que a brincadeira só tem sentido se for para aprender algo ligado à lista de números, cores, letras, formas etc. Por isso, defendemos que a formação dos professores da infância precisa alargar o território da compreensão de como as crianças aprendem e se desenvolvem. Não podemos adaptar os interesses propedêuticos construídos por uma história de educação infantil, pensada para a redenção da criança, especialmente a criança pobre, ao "dia da aula de arte" ou "dia da brincadeira".

A brincadeira, as interações e as diversas formas de expressão precisam compor as culturas das infâncias. Nossos espaços de educar crianças devem ser promotores de uma formação humanizadora e emancipadora, não um lugar de domesticação e imposição de regras que não dialogam com os processos de desenvolvimento em cada etapa vivida pela criança, como nos esclarece Elkonin (2017) ao discutir o problema da periodização.

Para ele, o problema da periodização do desenvolvimento psíquico da infância é um dos problemas fundamentais para as discussões da psicologia infantil. Suas pesquisas apontam para uma periodização pedagógica que não dialoga com a periodização psíquica, porque, geralmente, a periodização pedagógica trabalha com antecipações. Enquanto se discute a alfabetização das crianças pré-escolares e a inserção de tarefas do ensino fundamental para melhor preparar as crianças para a próxima etapa, Elkonin diz que a força motriz nesse período é a brincadeira na sua forma mais expandida: o jogo de papéis.

O sentido do brincar para o desenvolvimento psíquico das crianças de idade préescolar é múltiplo. Seu principal significado consiste no fato de que, por conta de procedimentos peculiares (a apropriação, pela criança, do papel da pessoa adulta e de suas funções sociolaborais, o caráter representativo generalizado da reprodução das ações objetais, a transferência dos significados de um objeto a outro etc.), a criança modela, no jogo, as relações entre as pessoas (ELKONIN, 20I7, p. I64).

Olhar de professor, Ponta Grossa, v. 24, p. I-24, e-17664.07I, 2021.

Disponível em <https://revistas2.uepg.br/index.php/olhardeprofessor> 
Elkonin explica que o principal significado do jogo de papéis é permitir que a criança desenvolva meios para compreender as relações entre as pessoas, apreendendo os fundamentos da atividade humana. No entanto, esclarece que "isso não significa que não exista um desenvolvimento simultâneo em outras direções. A vida de cada criança é multifacetada e as atividades, por intermédio das quais se realiza, são variadas" (2017, p. 168). Zaporózhets (1987) esclarece que as atividades plásticas, como desenho e a modelagem, agem juntamente com o jogo de papéis no desenvolvimento psíquico. Por isso, tais atividades devem estar presentes na rotina diária das crianças e não apenas em situações pontuais.

Apropriando-nos desses saberes, temos condições de pensar nossa prática pedagógica a partir dos eixos norteadores interações e brincadeira, pautados pela—Resolução n॰ 05/09 (BRASIL, 2009). Temos uma legislação avançada, mas precisamos efetivá-la na prática, garantindo, na formação dos professores, a apropriação desses conceitos e garantindo também a efetivação de práticas que ampliem as possibilidades expressivas das crianças.

\section{No cotidiano do CMEI Criar: estranhamentos, reflexões e novos olhares}

O lócus da realização da pesquisa foi um Centro Municipal de Educação Infantil - CMEl, que chamamos de CMEI Criar ${ }^{3}$, localizado na cidade de Manaus - AM. A escolha desse espaço ocorreu pelo fato de termos tido contato, por um período, com o grupo de profissionais, durante a formação ofertada pela Divisão de Desenvolvimento Profissional do Magistério - DDPM/SEMED, da qual participávamos na função de formadora do grupo Educação Infantil e Infância. Esse grupo demonstrou interesse nas discussões e se envolvia com os textos e propostas, tornando o espaço agradável e fomentador de reflexões. O convite foi realizado e aceito, mediante os trâmites legais do Comitê de Ética e Pesquisa e Secretaria Municipal de Educação. A diretora, a pedagoga e as seis professoras do turno vespertino aceitaram participar da pesquisa e atenderam aos critérios de seleção estipulados no projeto encaminhado ao Comitê de Ética e Pesquisa ${ }^{4}$.

Professoras de educação infantil têm familiaridade com o desenho da criança. Ele faz parte, com muita frequência, das propostas de trabalho nas pré-escolas. Mas qual o olhar que temos para essa forma de expressão? Como nossas experiências, concepções, ideias e conhecimento sobre o desenho orientam nossa prática diária com as marcas produzidas pelas crianças, com as transgressões feitas para aquilo que propomos?

Os significados construídos ao longo da formação de cada professora implicam diretamente na construção do olhar que acolhe ou rejeita o processo e produção da criança. Para Augusto (20|4, p.

\footnotetext{
${ }^{3}$ Nome fictício para resguardar a identidade do espaço.

${ }^{4}$ Projeto aprovado pelo Comitê de Ética e Pesquisa por meio do Parecer Consubstanciado n ${ }^{\circ}$ I.779.564.

Olhar de professor, Ponta Grossa, v. 24, p. I-24, e-17664.07I, 202 I.

Disponível em <https://revistas2.uepg.br/index.php/olhardeprofessor>
} 
36), "o ato de olhar para o desenho da criança pode significar tomá-lo como um objeto a ser considerado, cuidar para que desenvolva da melhor maneira, pensar sobre seu conteúdo. Significa, por extensão, pensar sobre os sujeitos desse olhar".

As visões sobre a própria capacidade de desenhar estavam presentes nas narrativas tecidas nos encontros do grupo de estudos. Segundo a professora Chaparro5: "Eles dizem: professora, eu não sei desenhar. Eu digo para eles: a professora também não sabe. Vamos tentar juntos?”. Entendemos que além de pensarmos o desenvolvimento expressivo das crianças por meio do desenho, precisávamos também pensar na formação estética e criativa das professoras, sujeitos constituintes da pesquisa. $\mathrm{A}$ compreensão sobre o desenho da criança passava pela compreensão de como essa apropriação se deu em cada uma delas e como agora, como profissionais, viam a necessidade dessa objetivação.

Segundo Vigotski6 (2010, p. 696), "para que o desenvolvimento de suas propriedades humanas específicas possa ocorrer de forma auspiciosa e boa, é obviamente imprescindível que essa forma final guie justamente - se é possível dizer dessa maneira, o desenvolvimento infantil desde o início". Vigotski explicava em A questão do meio na pedologia como a fala final, sofisticada, já dominada pelos adultos, é necessária para que as crianças possam desenvolver a própria fala e que se as crianças apenas conversassem entre si não haveria grande desenvolvimento, pois não estariam em contato com a fala mais elaborada.

Seguindo essa compreensão, defendemos que as crianças precisam conhecer formas superiores de atividades plásticas para perceberem que existem outras possibilidades de criação. Elas não ampliarão suas referências se apenas tiverem contato com os desenhos umas das outras. Professoras da escola da infância precisam oportunizar esse contato, mas isso só será possível se elas tiverem, primeiramente, esse acesso, o que é um desafio para nossa formação pessoal e profissional.

Pensar espaço, tempo e materiais disponibilizados às crianças para que elas se expressassem por intermédio do desenho mexia com muitas questões, especialmente sobre a formação da sensibilidade de adultos e crianças. As professoras e as crianças diziam não saber desenhar. As crianças diziam que o desenho dos colegas estava feio quando não havia representação figurativa. As professoras ocupavam-se com outras tarefas enquanto as crianças desenhavam. Algumas vezes, as crianças recusavam as propostas artísticas, porque recebiam a recomendação da família para manterem suas roupas e corpos limpos. Em alguns momentos, as professoras sinalizavam preocupação com as mesas,

\footnotetext{
${ }^{5}$ Cada participante escolheu como gostaria de ser identificada.

${ }^{6} \mathrm{O}$ nome do autor bielorrusso é transliterado para a Língua Portuguesa de diversas formas: Vigotski; Vygotski; Vygotskii; Vygotsky. Optamos pela escrita aportuguesada do nome, com exceção das referências a publicações que utilizam grafias distintas e que permanecem neste artigo em conformidade com a opção dos autores e/ou tradutores nos originais.
}

Olhar de professor, Ponta Grossa, v. 24, p. I-24, e-17664.07I, 2021.

Disponível em <https://revistas2.uepg.br/index.php/olhardeprofessor> 
paredes e roupas das crianças ou com a reação das famílias. Como abordar questões delicadas e necessárias sobre a formação do gosto, da percepção e do processo criador?

Esse somatório de observações apontou para a organização de encontros no grupo de estudos para pensar sobre o desenho dentro de um entendimento em que a necessidade da arte e a formação estética são direitos de todas as pessoas. Entendendo ao que os debates vinham nos instigando, era preciso refletir sobre o processo de formação de repertórios. O primeiro desenho pedido às professoras foi que registrassem as formas casa, árvore e figura humana.

Figura I - As casas, árvores e figuras humanas Professoras CMEI Criar

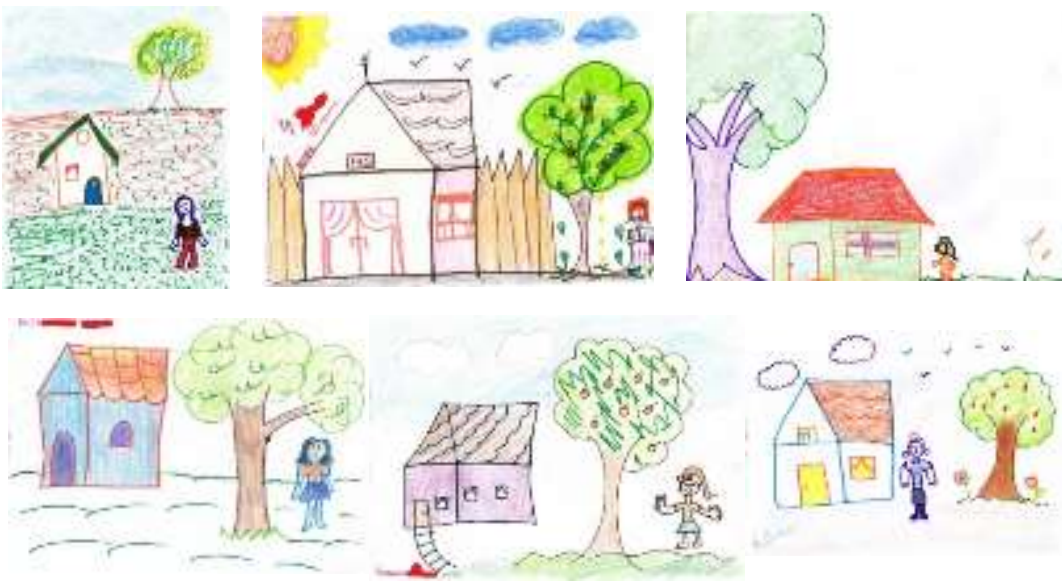

Fonte: PRINTES, 2018

Guardamos os desenhos e os expusemos no encontro seguinte. Quando as professoras chegaram, eles estavam fixados na parede. A professora Rosa foi a primeira a observá-los: "Acredita que eu não estava reconhecendo os desenhos? Eu estava procurando o meu. Aí depois eu vi o da Chaparro... Gente, foi o que nós fizemos! Aí eu fui atrás do meu. Tá ali, mas eu não conheci”. Diante das semelhanças entre as imagens, a professora Luciana ponderou: "Eu estava procurando o meu e não achei também".

Nesse dia, levamos uma sequência de casas, de diferentes formas e materiais, que foi observada pelas professoras. Ao chamarmos a atenção para as semelhanças entre os desenhos, as professoras defenderam que foram suas referências que lhes oportunizaram essas construções, que apesar de conhecerem outros tipos de moradia e outras árvores, são essas formas as mais comuns na nossa região. Segundo a professora Cacau, "as nossas árvores são assim. Copa verde e caule marrom". "Olha a nossa mangueira. É caule marrom e copa fofinha. É a nossa referência. Dificilmente a gente vai ver aqui na região amazônica árvores diferentes", observou a pedagoga Idê, que acrescentou:

Os nossos desenhos têm a referência da nossa vida escolar, porque sempre tinha modelos para seguir e muitos dos nossos traçados hoje são limitados por conta disso, porque a gente não tinha essa possibilidade de quebrar vidros [fazendo referência ao

Olhar de professor, Ponta Grossa, v. 24, p. I-24, e- I7664.07I, 202 I.

Disponível em <https://revistas2.uepg.br/index.php/olhardeprofessor> 
texto "Quando a escola é de vidro, de Ruth Rocha], de inventar para além. Eu lembro de um trabalho no magistério, na aula de arte, que a professora no começo dava modelos, mas depois ela deixou livre. E daí tu vais te virar como? Se tu estás acostumado a sempre seguir aquilo. O que eu tinha como base? Aquilo que foi bom para mim, eu quero reviver. $O$ desafio da escola é esse. Tem de quebrar esse vidro.

Aquilo que foi bom para mim e eu quero reviver, como disse a pedagoga Idê, é uma boa explicação para nosso reduzido repertório de desenho. De alguma forma, aprendemos a representar algumas coisas, como casa, árvore, figura humana, barco, sol, nuvens, pássaros, flores, frutos, grama. Com esses elementos, nos livramos daquela aflição sentida por Exupéry, quando os adultos não entendiam seu desenho, e reproduzimos, quase sempre, os mesmos traços. E porque nosso repertório é reduzido e figurativo, temos dificuldade de apreciar e trabalhar outras formas de expressão, negandoas com uma frase muito ouvida em exposições ou sobre obras conceituais e contemporâneas: isso não é arte.

Essa defesa do que é ou não arte geralmente parte da herança recebida em nossa formação, quando se instaurou a Academia Imperial de Belas Artes, em 1816, trazida pela Missão Artística Francesa, que valorizava o desenho como cópia fiel dos modelos europeus neoclássicos e desvalorizava a arte que não seguia esse padrão (MARTINS; PICOSQUE; GUERRA, 1998).

Mesmo apreciando a forma figurativa dos desenhos infantis é preciso entender que, desde os primeiros rabiscos das crianças até a chegada no desenho representativo, uma longa jornada de marcas foi construída (PRINTES, 2018) e que toda ela é necessária para o desenvolvimento da expressão e criação. A valorização apenas do desenho figurativo desconsidera todas as outras formas de expressão gráfica. Segundo Derdyk (2010, p. 20):

A instrumentalização do educador requer a vivência da linguagem gráfica, pois constata-se lacunas na formação, seja pelo sistema escolar, seja por impedimento de ordem familiar, social e/ou cultural. A vivência prática propicia ao educador mais perguntas, confrontos, espelhamentos, delineando possibilidades expressivas, principalmente quando se tem à mão novos repertórios gráficos, que atualizam e preenchem estes vácuos em nossa formação. Quem sabe, a partir do reconhecimento da própria capacidade de desenhar, possa surgir um novo significado no encontro entre adulto e criança.

Durante os encontros do grupo de estudo, a temática central orbitou sobre a necessidade e valorização do processo criativo da criança e não apenas do produto e sobre a formação estética dos sentidos, o que enfatiza a responsabilidade da escola da infância de ampliar os repertórios e vivências culturais, estimulando a experimentação. Para isso, precisávamos discutir sobre as possibilidades de criação de condições para o alargamento das referências artísticas das crianças.

Trouxemos para fomentar o debate a leitura dos textos Educação Infantil e arte: sentidos e práticas possiveis (OSTETTO, 20II), Criação e Imaginação (VIGOTSKI, 2009), Imaginação e realidade 
(VIGOTSKI, 2009) e $O$ desenho da criança (SILVA, 2002). Os textos base dialogaram entre si de forma significativa. Silva nos situa com um breve histórico sobre as pesquisas relacionadas ao desenho e as abordagens adotadas por elas, a constituição social do desenho da criança e a relação entre desenho, fala e o outro. Vigotski discute a relação entre criação, imaginação e realidade, explicando a necessidade de ampliação das experiências, contato com a cultura e com o outro e o caráter afetivo dessa relação. Ostetto traz a relação entre crianças, arte e educação infantil, nos instigando a pensar como cultivar e acolher o ser poético das crianças e como ampliar os repertórios e possibilidades de expressão por meio da educação estética.

Os textos teciam entre si uma trama de convite à percepção de um olhar que acolhe, um olhar carregado de sensibilidade. Defendermos a necessidade da arte na formação humana parte da premissa de que a educação do nosso olhar é um movimento social. Marx (2008, p. I I0) afirmou que "a formação dos cinco sentidos é um trabalho de toda a história do mundo até aqui”. Para Fischer (1976, p. 252):

[...] assim como a linguagem representa em cada indivíduo a acumulação de milênios de experiência coletiva, assim como a ciência equipa cada indivíduo com o conhecimento adquirido pelo conjunto da humanidade, da mesma forma, a função permanente da arte é recriar para a experiência de cada indivíduo a plenitude daquilo que ele não é, isto é, a experiência da humanidade em geral. A magia da arte está em que, nesse processo de recriação, ela mostra a realidade como passível de ser transformada.

Houve uma relação de identidade entre as professoras e os textos por se aproximarem da rotina vivida por elas no espaço do CMEI Criar, mas também foram geradores de indagações: $O$ que dispomos nas paredes do prédio? Que tipo de materiais oferecemos para as crianças? Qual a relação estabelecida com o tempo? Precisamos legendar o desenho? É preciso controlar a "sujeira" de uma aula de arte?

A defesa da ampliação de repertório parte da premissa de que conhecer os elementos da realidade possibilita o movimento das relações possíveis entre imaginação e realidade, bases do ato criador. Assim, quanto mais ricas e diversas forem as experiências vividas pelas pessoas, mais repertório haverá para a construção do processo de imaginação e criação. llustramos com o poema de Alexander Puchkin apresentado por Vigotski (2009, p. 21 ):

$\mathrm{Na}$ enseada, há um carvalho verdejante

Nesse carvalho, há uma corrente de ouro,

E um gato sábio, de dia e de noite,

Anda em círculos pela corrente.

Ao ir à direita, canta uma canção;

Vai à esquerda, conta um conto.

Lá há magias e silvanos,

E uma sereia nos galhos;

Lá nas trilhas maravilhosas,

Há pegadas de animais nunca vistos;

Olhar de professor, Ponta Grossa, v. 24, p. I-24, e-17664.07I, 202 I.

Disponível em <https://revistas2.uepg.br/index.php/olhardeprofessor> 
A isbá lá tem patas de galinha,

Não tem janelas nem portas.

Vigotski explica que só é possivel imaginar a lzbuchka (diminutivo de isbá, nome dado à casa camponesa de madeira) sobre patas de galinha, porque se conhece o que é casa e o que é galinha. Os elementos fantasiosos da narrativa de Puchkin trazida por Vigotski só são passíveis de combinação e construção mediante as experiências reais humanas. "Quanto mais a criança viu, ouviu e vivenciou, mais ela sabe e assimilou; quanto maior a quantidade de elementos da realidade de que ela dispõe em sua experiência [...], mais significativa e produtiva será a atividade de sua imaginação" (VIGOTSKI, 2009, p. 23).

Ostetto (20lI, p. 5) nos desafia a pensar uma educação estética na educação infantil que possibilite "[...] ampliar o olhar da criança sobre o mundo, a natureza e a cultura". Para isso, ela afirma que o professor precisa ser um interlocutor privilegiado, aquele que criará as condições para a circulação dos bens culturais e dará suporte à criação infantil. Por isso, ainda é necessário refletir sobre como podemos desenvolver a educação estética na nossa própria formação.

Seguindo nossa proposta de observação e exploração textual e visual no grupo de estudos, apresentamos uma sequência de obras de Piet Mondrian, pintor holandês modernista e fundador do movimento Neoplasticista, que defendia uma total limpeza espacial para a pintura, apresentando seus elementos mais puros. Essa mudança é perceptível nas obras selecionadas, uma sequência de quatro pinturas, realizadas entre 1907 e 1912, usando o tema árvore.

Figura 2 - Bomen aan het Gein: a lua nascente (1907, 1908) - Mondrian

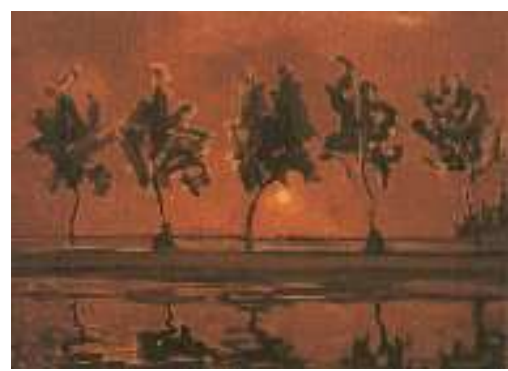

Fonte: Acervo do Museu Municipal de Haia, $2021^{7}$

\footnotetext{
${ }^{7}$ O museu é conhecido por ter o maior acervo mundial das obras de Piet Mondrian. Disponível em: https://www.kunstmuseum.nl/nl/collectie/zoeken/?origin=gm\&search=mondriaan
} 
Figura 3 - Árvore vermelha (1908) - Mondrian

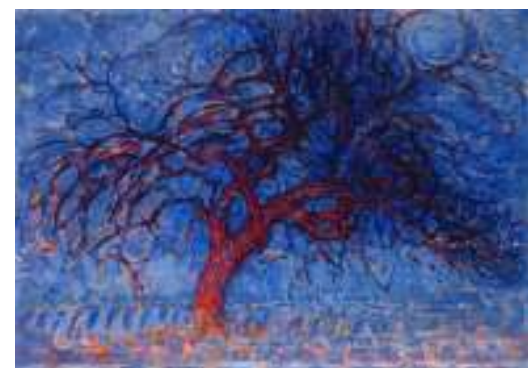

Fonte: Acervo do Museu Municipal de Haia, 202I

Figura 4 - Árvore cinza (19II) - Mondrian

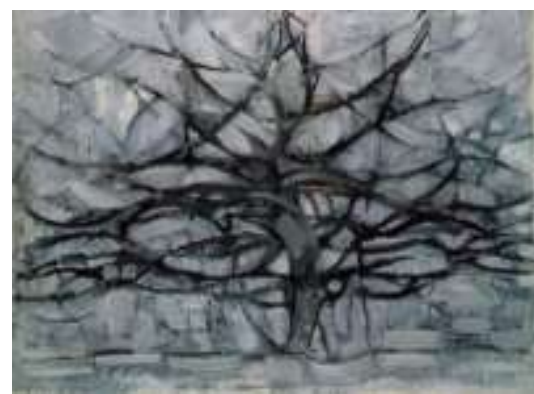

Fonte: Acervo do Museu Municipal de Haia, 202I

Figura 5 - Macieira em flor (1912) - Mondrian

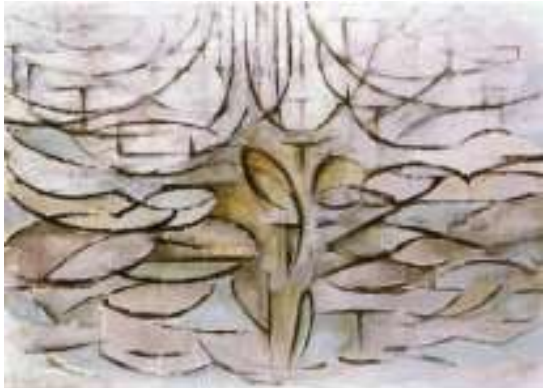

Fonte: Acervo do Museu Municipal de Haia, 202I

As professoras logo observaram e mostraram sua inquietação em várias sentenças: "Parece que ele foi desaprendendo"; "Todas elas são árvores?”; "Essa chama macieira em flor. Mas cadê as flores?"; "Parece que foram pintadas no azulejo"; "Parece que as folhas estão caindo, como se tivesse só os galhos secos"; "Parece as estações do ano"; "Se eu fosse dar nome, chamaria vida, sertão, inverno e pôr do sol”; “É que ele não é realista”; “A árvore está desmaterializada”; “Isso é uma macieira, é?”.

As angústias e inquietações das professoras sobre a descontrução proposta por Mondrian suscitaram, inicialmente, uma rejeição daquilo que viam, pois à medida em que os anos avançavam, o trabalho do artista ficava menos realista. Segundo Gombrich (p. 582, 2015), Mondrian "ansiava por uma arte de clareza e disciplina que refletisse, de algum modo, as leis objetivas do universo [...] e queria que sua arte revelasse as realidades imutáveis subjacentes nas formas em permanente mudança da 
aparência subjetiva". Gombrich ainda reflete que o processo de criação do artista abstrato pode causar muito mais preocupação que um artista imbuído de ideias tradicionais, como a pintura de um retrato, pois ele sabe onde chegar, porque a tradição assim lhe diz e isso não ocorre ao pintor abstrato.

A partir dessas observaçõs, usamos as orientações do material do PESC $^{8}$ (CUNHA, 20I I), que indica caminhos para a leitura de obras de arte. Ele destaca que não há um único modo de ler, mas que podem ser observados os aspectos formais da obra, os elementos que a compõem, como linha, cor, volume, perspectiva etc., que é importante observar o contexto histórico da criação, e ainda, fazer uma leitura interpretativa, em que não há certo e errado, porque se dá a partir da vivência de cada um, das percepções que se tem.

Pillar (2014) nos assegura que ler é atribuir de significado aquilo que lemos, seja um texto ou uma imagem. Para Vigotski (1999), o desenvolvimento da sensibilidade dos adultos e crianças é condição para o desenvolvimento das artes e para sua apreciação, para provocar uma reação estética, um diálogo sensível entre a obra e aqueles que a recebem.

Seguindo a ideia de promoção de experiências, fomos vivenciando com as professoras possibilidades de propostas que indicassem pontos de partida para o planejamento daquilo que podia ser possível apresentar às crianças. Para além da necessidade de ampliação de repertórios artísticos, que perpassa pelas variadas manifestações artísticas presentes no poema, na pintura, na dança, na fotografia, na música, no cinema, na escultura, na dramatização e na literatura, ainda havia a condição concreta de produção de propostas que demandam materiais específicos e a carência deles nos CMEls.

Diante de tais condições, a partir das pesquisas que fizemos (TSUHAKO, 2017; IAVELBERG, 2013; DERDYK, 2010), apresentamos às professoras uma proposta de organização do desenho partindo de três bases, possibilitadoras de várias combinações. Ao pensarmos as propostas de desenho, era necessário levarmos em consideração o movimento do corpo, a superfície que recebe a marca e o que usamos para produzir essa marca. Com a contribuição das professoras, construímos o seguinte quadro (que pode ser constantemente atualizado a partir das experiências de crianças e professores):

\footnotetext{
${ }^{8}$ Programa de Ensino Sistematizado de Ciências, PESC Ciências - Brincar e aprender foi adquirido pela Secretaria Municipal de Educação no ano de 2013. Consiste em uma unidade experimental com jogos e experimentos, que contemplam ciências, linguagem oral e escrita e arte (CUNHA, 20I I).
} 
Quadro I - Possibilidades para pensar a organização do desenho
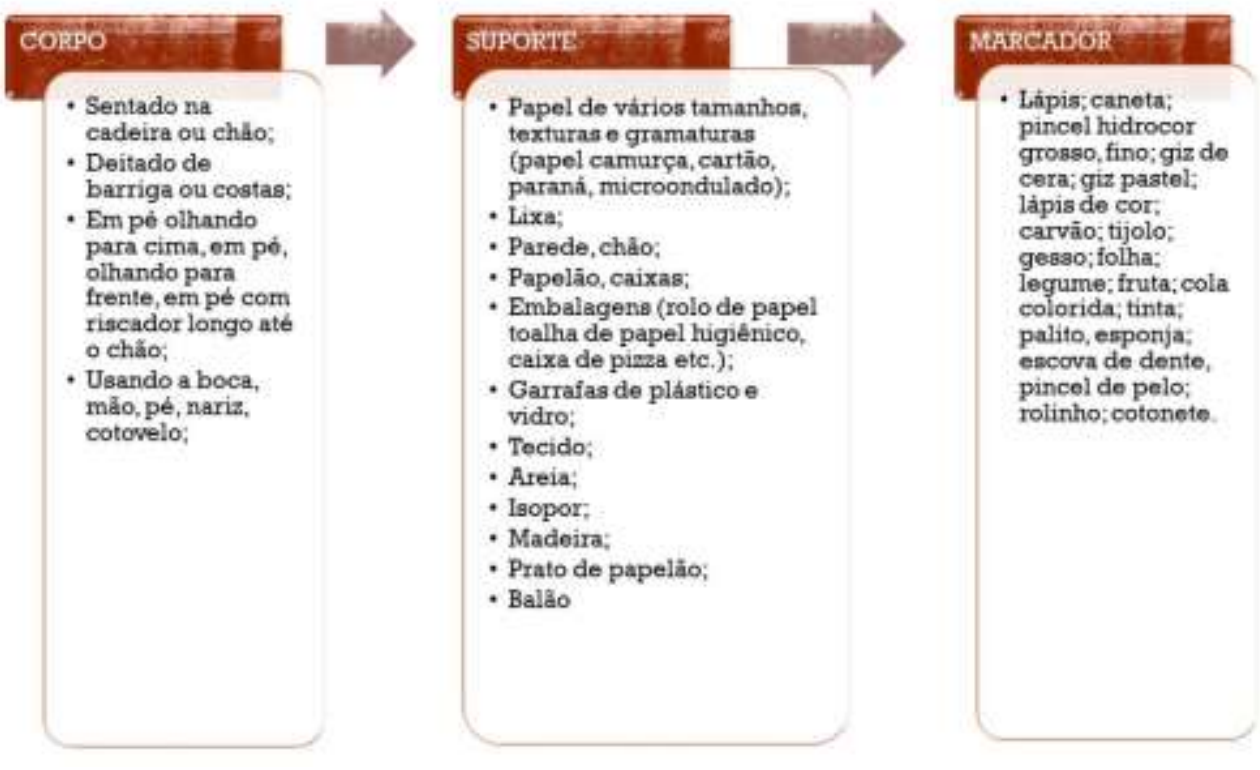

Fonte: PRINTES, 2018

Quando começamos a instigar esse olhar sobre o movimento do corpo, vimos que é possível usar a mesma superfície e o mesmo marcador de maneiras diferentes. A forma comum de as crianças desenharem era sentadas em suas cadeiras, com o apoio das mãos na mesa, usando papel A4 branco, lápis de cor e giz de cera.

A partir dessa observação, propusemos variadas possibilidades de pensar propostas com o corpo da criança e com materiais disponíveis na escola, além da inserção de materiais inusitados e comuns, como embalagens e caneta, como questionou a professora Chaparro: "A criança pode desenhar com caneta? Mas se ela fizer com caneta e errar? Não vai conseguir apagar". Na reunião de avaliação da pesquisa, a professora Chaparro lembrou do próprio questionamento sobre o uso da caneta pelas crianças e contou que "até caneta eles já usam agora. Eu fiquei pensando quando você me perguntou por que não pode usar caneta. Eu pensei: Ué? Por que não pode usar caneta? Agora eles me perguntam: Posso fazer o desenho com caneta? E eu digo que pode".

Para experimentarmos as propostas sobre as quais estávamos discutindo, propusemos às professoras que desenhassem novamente uma árvore, mas mudaríamos o movimento do corpo, as superfícies e marcadores: em pé, com papel camurça cortado em tiras finas e fixado na parede, mudamos a forma do papel e sua textura, além da textura da parede ao fundo, o que imprimiu marcas diferentes daquelas primeiras árvores, desenhadas em papel ofício, no início do encontro. Para a professora Luciana, "desenhar na parede, no papel camurça, foi legal. A estrutura da parede é diferente, também ajudou na hora de desenhar". A observação da professora Chaparro foi que "a textura do 
camurça é muito gostosa. Quando eu desenhei no camurça, mudou o meu desenho, porque o formato era diferente, estava mais delimitado".

A marca produzida por um giz de cera no papel sulfite branco é muito diferente da marca deixada pelo mesmo giz de cera em papel camurça. Mudando as texturas, as marcas mudam em intensidade e cor. A mudança no tamanho do papel também é um fator interessante, que promove mudanças na organização do espaço destinado ao desenho. $O$ papel camurça, que era um material pouco usado antes, logo se tornou um grande achado para as crianças e professoras, que passaram a experimentá-lo em cores e posições diversas.

Continuamos discutindo com as professoras as possibilidades de combinação apresentadas no quadro. Algumas já haviam sido exploradas por elas ao longo do ano, conforme elas se sentiam instigadas. Muitas outras foram surgindo, fruto de suas pesquisas e experiências. Para além do que registramos no quadro, outras propostas foram partilhadas à medida que as experiências aconteciam. Os espaços físicos e mobiliário passaram a compor o repertório de criação. Já não se desenhava mais apenas sentado e nem somente mais sobre o papel sulfite. Suportes diferentes passaram a estar cada vez mais presentes.

Elas já haviam experimentado com as crianças o desenho no papel ofício, embaixo da mesa e das cadeiras, após ouvirem como os afrescos eram feitos. Propusemos para elas essa experiência também. Mas quando elas deitaram para ver a superfície sobre a qual fariam sua composição inicial de casa e árvore, não encontraram papel ofício colado embaixo da mesa, mas um prato de papelão com ondulações. A proposta era perceberem como a mudança na superfície pode alterar a forma como as marcas são produzidas. A pedagoga Idê observou logo que o braço ficou cansado, mas a professora Chaparro estava animada com a experiência e relatou: "Desenhei completamente diferente agora. Me deu vontade de fazer outras coisas. Minha casa está lá no morro".

Oferecemos carvão vegetal próprio para desenho e papel criativo dobra-cor. A experiência com o carvão, a maneira como ele deslizava no papel e como sujava a mão foram observações destacadas. $\mathrm{E}$ os desenhos novamente sofreram mudanças. Mudaram a superfície, o marcador e o corpo. As árvores não eram mais de copas frondosas e caules grossos. As referências foram reconfiguradas com a inserção de elementos que interferiam na representação.

Foram apresentadas outras possibilidades de superfície, como tecido, papel paraná, folhas de revistas e jornais, lixa, embalagens de isopor e de papelão, cuba de ovo, rolo de papel higiênico e papel toalha, cartolina, papel microondulado, papel cartão e papel dupla face, que podem sem cortados em tamanhos e formas variadas. Também apresentamos marcadores diferentes, como pincel para tecido, pastel oleoso, nanquim, lápis de cor aquarelável, lápis de cor misturinha (cores misturadas em um mesmo lápis) e maquiagem (especialmente batom). 
Debatemos sobre as condições necessárias para o desenvolvimento do ato criador e a ênfase apontada por Vigotski (2009) para que elementos da realidade componham o repertório da criança, ressaltando a dependência entre imaginação e experiência. Com o texto de Silva (2002), discutimos as principais correntes que viam o desenho como um ato evolutivo natural e como vemos o desenho a partir do olhar da teoria Histórico-Cultural, que é social e desenvolvido nas relações com os pares e com pessoas mais experientes.

No encontro seguinte, convidamos André, aluno do curso de Artes Visuais da UFAM, para participar conosco. Ter alguém das artes junto conosco foi bem interessante, especialmente por uma fala desmitificada, de que não há gênios criadores. André apresentou conceitos e imagens com o tema Introdução a Técnicas de Desenho: Liberdade e Criatividade e começou perguntando qual era nossa interação com a arte, quem gostava de desenhar e qual a relação que tínhamos com o desenho. $\mathrm{A}$ professora Luciana revelou: "a vontade de aprender é grande, especialmente pintar em tecido, mas tenho muita dificuldade". A professora Chaparro contou: "fico encantada com pessoas que sabem desenhar, com quem sabe tatuar. Eu acho maravilhoso e gostaria muito de saber desenhar. Eu tenho dificuldade. Mas depois desses estudos, eu estou tentando melhorar meus traçados”. A professora relatou: "desenho só se tiver uma base, uma referência. Gosto muito do desenho, da pintura, da dramatização e estou à procura de conhecer mais". A pedagoga Idê disse:

Eu estava pensando aqui. Eu gostava muito de desenhar. Agora não mais. Você vai perdendo a habilidade se você não treina. Eu tinha um caderno de desenho. Eu gostava muito de desenhar. Para eu não estar mexendo com os outros, eu desenhava. Ao invés de eu estar pintando o sete [risos], eu desenhava. Eu ampliava, eu diminuía, imaginando e tentando fazer, sem copiar. Eu comecei com aquela técnica de fazer no quadriculado. Aí depois eu não precisava mais, porque já conseguia fazer direto. Eu fiz até um quadro com pirógrafo na madeira. Mas depois eu fui deixando e hoje eu não consigo mais fazer. Perdi a habilidade.

Após os relatos, André questionou: "Vocês afirmam 'eu não sei desenhar', mas com base em quê?". Explicou que na arte há muitas formas de expressão e técnicas, que quando dizemos que não sabemos, quem estamos usando como referência? Apresentou a definição de desenho e mostrou os usos do croqui, ilustração, caricatura, cartoon, grafite e desenho minimalista. Abordou brevemente as principais características dos movimentos surrealista, modernista e expressionista. Explicou às professoras as técnicas de aquarela, nanquim aguado, hachuras e doodle art e, por fim, propôs a experiência do doodle arts (desenhos criados livremente) e da aquarela (intensidade das cores, sobreposição), o que animou as professoras. "Vamos sujar, sem preocupação", observou a professora Chaparro. "Eu vou fazer igual aos meninos, vou usar várias cores e misturar tudo. Não olhar para o do outro. Eu não estou nem olhando para não me influenciar", disse a professora Rosa enquanto criava. 
Figura 7 - Criações de aquarela sobre papel Professoras do CMEI Criar

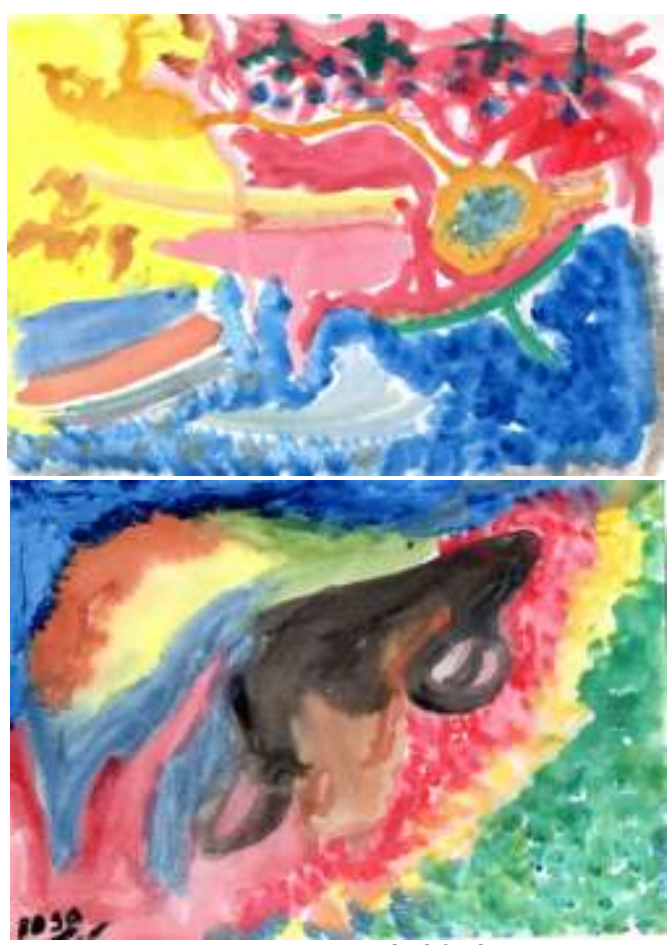

Fonte: PRINTES, 2018

As professoras foram muito receptivas à fala trazida por alguém que estuda especificamente nosso objeto de pesquisa. A ênfase de que todos podemos aprender e a necessidade de exercitar foram as mensagens principais. $O$ uso de tinta para aquarela e a fuga de desenhos figurativos identificáveis foi um exercício muito importante para as desconstruções que fomos fazendo ao longo do estudo e observações das crianças. Era importante que elas experimentassem a possibilidade de desenhar de outras formas. Não demorou para que os novos e ressignificados elementos passassem a fazer parte do repertório das crianças.

\section{A liberdade, o encantamento e a transgressão: crianças, corpos, materiais e marcadores}

Procurávamos instigar as professoras acerca daquilo que vínhamos estudando para que elas percebessem, no planejamento diário com as crianças, possibilidades de construção de experiências com as linguagens artísticas. Era uma formação continuada no dia a dia, pois estávamos frequentemente dialogando a partir das leituras e discutindo sobre atividades diferenciadas para as crianças, além de oferecer leituras complementares, conforme as necessidades individuais surgiam.

A partir do avanço das discussões e à medida em que se sentiam mais confiantes para explorar outras possibilidades, especialmente após terem experimentado o movimento do corpo, os materiais 
e os marcadores, sentindo-se desafiadas a acolher o ser poético da criança, arriscavam-se em propostas novas e desafiadoras.

Com as mudanças nas propostas, vimos as professoras junto das crianças e não mais se ocupando de tarefas burocráticas enquanto elas desenhavam, porque estavam calmas. $O$ estar junto proporcionava a observação da fala das crianças, das relações estabelecidas com as próprias vivências e as experiências dos outros. As trocas com a professora e com os colegas ajudam a organizar a percepção da criança, orientando sua atenção e seu comportamento. A fala é um recurso de mediação entre a criança e o outro e com ela mesma, o que lhe possibilita orientar a própria conduta (VYGOTSKI; LURIA, 2007), por isso ela é tão importante e deve ser privilegiada na escola na infância em lugar do silêncio, ainda tão valorizado como sinônimo de turmas bem comportadas e controladas.

Observamos que quanto mais variadas eram as propostas, mais as crianças se interessavam e conversavam sobre elas. Como os resultados eram diferentes conforme a posição do corpo, da superfície e do marcador, a avaliação das crianças em apontar critérios para o que era bonito ou feio foi sendo substituída pela observação das diferenças do resultado a que cada uma chegou. Isso produziu uma nova cultura do olhar entre elas e entre as professoras. Processo e produto em diálogo e a constatação de que

Há uma grande diversidade de formas de encontro da criança com seus pares, como a apresentação do modelo, o pedido de ajuda, o auxílio para desenhar uma determinada figura, os comentários verbais. Estes intercâmbios são imprescindíveis, e simultaneamente inerentes à situação de desenho na escola, constituindo o desenvolvimento do grafismo e da própria criança como indivíduo que se forma e se transforma na dialética das relações sociais (SILVA, 2002, p. 33-34).

Uma questão apontada logo que apresentamos a pesquisa e discutida em outros momentos era a impossibilidade de se fazer propostas que demandavam muita atenção das professoras, e que estas, por não terem auxiliar, não viam possibilidades de atender devido ao grande grupo de crianças. Propusemos às professoras pensar na organização por rodízio. Não era necessário que todas as crianças fizessem tudo juntas, ao mesmo tempo. Se uma proposta demandava mais atenção da professora, as outras crianças poderiam estar envolvidas em propostas mais autônomas. Foi a aceitação dessa forma de organizar o espaço que permitiu o alargamento das experiências, como comentou a professora Rosa, na reunião de avaliação:

A experiência de contar história e brincar com a caixa foi feita em rodízio, porque não tinha caixa para todo mundo. Então, enquanto uns brincavam com as caixas, outros faziam outras atividades. E como eles tinham que aguardar a vez, eles aprendiam a esperar, a desenvolver a paciência. Crianças que antes não conseguiam esperar, aprenderam a esperar o rodízio tranquilamente.

Olhar de professor, Ponta Grossa, v. 24, p. I-24, e-17664.07I, 202 I.

Disponível em <https://revistas2.uepg.br/index.php/olhardeprofessor> 
Usando os mesmos papéis e canetinhas, a mesa virou de lado e se transformou em cavalete ou as crianças foram parar embaixo das cadeiras para compor afrescos. Os materiais já eram conhecidos, os movimentos dos corpos não. Assim surgiam novas e divertidas criações.

As paredes e o chão passaram a ser importantes apoios para a exploração de novos materiais, como usar batons para desenhar nos grandes papeis $40 \mathrm{k}$, colados em sequência na parede. Era a primeira vez que podiam usar com permissão o batom para tal função. $O$ dedo corria em cima das marcas logo depois que as formas surgiam. Era mais que desenho, era uma experiência de sentidos, porque não era incomum encontrar crianças cheirando ou redesenhando com o dedo para ampliar a investigação desse inusitado material.

Em um círculo formado pelas crianças, a professora Regina sugeriu que usassem as costas do amigo da frente para apoiar o desenho e o inusitado compunha as tardes regadas a risos e animação. Em uma dessas tardes, combinou-se com as famílias que todos viriam de sandálias. Nesse dia, a mão ganhou um descanso, pois não foram elas a usar as tintas para criar uma obra coletiva: foi um trabalho a muitos pés. Inicialmente, as crianças ficavam receosas e perguntando se podiam mesmo fazer aquilo. Foi assim com as variadas propostas nas quais havia tintas e corpos em diálogo. Inicialmente, também havia famílias que reclamavam dos respingos de materiais nas roupas, calçados ou cabelos, mas elas compreenderam as necessidades das propostas à medida em que as professoras explicavam os objetivos durante as reuniões e porque viam suas crianças felizes ao poderem exercitar a criação com liberdade.

Observando os materiais disponíveis no depósito do CMEl, descobrimos uma caixa de papel de fax (material que foi enviado pela secretaria mesmo não havendo fax na escola). Foi um achado! Mostramos às professoras como trabalhar com álcool em um papel termossensível. Dele resultaram variadas criações, desde carimbo de partes do corpo ao desenho com dedo, pincel de pelo, esponja e cotonetes. As crianças ficavam maravilhadas com a "mágica" que o álcool produzia nas folhas. À medida que a ideia se disseminava e se popularizava em outros CMEls, o papel de fax passou do status de material esquecido no depósito para material disputado.

Caixas pintadas de branco pelas crianças passaram a ser suporte para as criações e depois eram expostas pelos corredores como grandes peças de móbiles, assim como os cilindros de papel higiênico, papel toalha, plástico filme. Na primeira vez que a professora Claudia ofereceu rolinhos para as crianças desenharem, uma delas primeiro os amassou para então começar a desenhar. Percebendo que os demais não haviam feito isso, foi até a professora e pediu outro rolo. Com o segundo, não conteve a força e acabou amassando algumas partes. Pediu um terceiro e finalmente se deu por satisfeita por conseguir deixar marcas em uma superfície não plana, como sempre havia trabalhado. 
Após assistirem a uma reportagem sobre pintores de bocas e pés, as crianças foram desafiadas a segurar o pincel com a boca, produzindo uma sequência de imagens que não eram mais possíveis de classificação. Não havia mais feio ou bonito usando a referência figurativa como padrão, mas parecidos e diferentes quando observavam os trabalhos expostos na parede da sala.

Outra experiência abstrata foi uma proposta pensada a partir da observação das obras de Jackson Pollock. A professora Regina juntou várias tampas de papelão em que cabiam uma folha tamanho A4 (tampas de caixas de resmas de papel A4 são perfeitas). O papel foi fixado dentro da tampa com um pedaço pequeno de fita adesiva e as crianças distribuíram pequenas porções de tintas coloridas. Em seguida, bolinhas de gude eram colocadas dentro da caixa, que foi movimentada em todas as direções. $O$ resultado é uma explosão de cores que se atravessam e lembram a técnica empregada por Pollock na produção de suas grandes obras.

As ideias das superfícies e marcadores foram se ampliando também com a ajuda das crianças, que enxergavam potencialidades nos objetos cotidianos da escola e de suas casas. Tampas, embalagens de papelão, bandejas de isopor, esmaltes, papel alumínio, luvas, tintas e massinha caseira foram novos e diferentes materiais inseridos pelas professoras, assim como o carvão e a aquarela, que passaram a compor os materiais que se avolumavam à disposição do exercício da expressão. Não havia mais entre as crianças e professoras a dúvida sobre a própria capacidade de usar o gesto, a linha, as cores e as formas. Não havia mais a negação das propostas. Na reunião de avaliação, a professora Heloiza disse:

\begin{abstract}
Pudemos observar o encanto das crianças na descoberta desse novo olhar. Foi interessante vê-las observando a construção que tinham feito e observando a construção dos colegas também. Inovar com aquele mesmo material que já usamos todos os dias, como a Rosa colocou, era tinta guache que eles já usavam, porém, quando a gente começou a colocar novas técnicas, não era mais só a tinta guache. As aulas se tornaram mais interessantes e havia liberdade de criar, que, para mim, foi o que mais me encantou. As crianças não tinham mais aquela ideia "Ah, eu não vou fazer porque eu não sei desenhar". Essa ideia de que eu não sei desenhar foi abolida do vocabulário deles, não usavam mais essa expressão. A sensibilidade do olhar deles para a produção dos colegas, olhar sem comparar, elogiar a produção dos colegas, com respeito. Elas deixaram essa ideia que só sabe desenhar aquela pessoa que é grande ou só desenha quem sabe desenhar.
\end{abstract}

A professora Regina comentou que as crianças estavam mais felizes. Sabemos o quanto as atividades artísticas podem ser criadoras de um ambiente mais leve e prazeroso e o impacto que isso causa nos sentidos que as crianças atribuem à escola, ao que fazem, a si mesmas. Como viemos afirmando ao longo do texto, o desenho é uma das formas pelas quais as crianças mais se expressam. É uma das formas como elas objetivam as aprendizagens presentes nas relações que vivenciam. Nesse movimento de apropriação-objetivação, a criança vai se humanizando.

A transgressão faz parte do processo artístico da criação das crianças. Elas dificilmente seguem na íntegra o proposto. Arriscam-se por outras possibilidades, distintas daquelas apresentadas ou 
sugeridas. "A área artística tem na transgressão a mola propulsora de sua construção" (LEITE; OSTETTO, 2012, p. II). Como nós lidamos com esses "desvios"? Nosso olhar tem sensibilidade para perceber além do não cumprimento das orientações? Estamos abertas para acolher a poiesis (capacidade de criação) da criança? Refletir sobre nossas preocupações nos permite pensar o valor que damos a questões que, historicamente, são colocadas como importantes na educação infantil, mas são fruto de senso comum. A obediência, a limpeza, o cumprimento de horários rígidos e o silêncio são algumas questões que devem ter seus porquês debatidos. Para Mello (2007, p. 85):

$$
\begin{aligned}
& \text { Estimulados - e mesmo pressionados - por pais e mães que creem possível e } \\
& \text { desejável antecipar a aprendizagem do Ensino Fundamental, professores e } \\
& \text { professoras da Educação Infantil criam salas de aula com rotina, espaços, relações e } \\
& \text { expectativas típicas do trabalho educativo com as crianças do Ensino Fundamental. }
\end{aligned}
$$

Mas precisamos resistir ao movimento de encurtamento da infância, adverte Mello (2007). E elas também lutam por isso, por esse espaço de aprender e se desenvolver como crianças. $O$ olhar sensível acolhe as transgressões das crianças, pois elas são experimentos, são tentativas, são os sentidos em movimento.

As professoras, desafiadas também a desenvolver sua poética pessoal, foram acolhendo as invenções das crianças, algumas vezes transgressoras e, muitas vezes, poéticas, mas só possíveis de serem vistas pelo desenvolvimento do olhar sensível. Saímos desse processo com as descobertas de que o desenho é uma linguagem rica e capaz de gerar aprendizagens, desenvolvimento dos sentidos e expressão. Nesse movimento, também reconhecemos a necessidade da arte para a formação humana e da ampliação de repertórios, pois "o ato de conhecer transforma o conhecimento e o sujeito que o conhece" (KONDER, 20I3, p. 37).

\section{Conclusão}

Nossa compreensão aponta que a defesa da ampliação de repertórios das crianças e da multiplicidade de novas e diferentes experiências estéticas mediadas pela escola da infância passa pela necessidade de ampliação de repertórios dos professores e professoras que organizam os espaços, tempos e materiais ofertados às crianças. A formação inicial e continuada carrega em seu bojo a necessidade do alargamento das referências culturais vividas. Construímos um processo marcado pela mudança do olhar sobre a produção das crianças a partir do momento em que também ampliamos as propostas que eram oferecidas acerca do movimento do corpo e dos materiais.

Um fato interessante aconteceu em uma oficina de arte que realizamos com as crianças. Em parceria com as alunas estagiárias do curso de licenciatura em Pedagogia da UFAM, organizamos em 
cada uma das seis salas uma proposta, para que as crianças, em rodízio, passassem por todas elas. A sala 05 foi organizada para ser o espaço da pintura em cavalete (feitos de papelão).

Não havia uma orientação direta sobre o que as crianças deveriam criar, mas colamos pela sala as impressões de obras de vários artistas que havíamos apresentado às professoras: Joan Mitchell, Van Gogh, Miró, Kandinsky, Velásquez, Hokusai, Picasso e as árvores de Mondrian. As tintas e os pincéis estavam dispostos para que fossem usados livremente. Professoras, estagiária e uma mãe de alunas estavam para auxiliar conforme as crianças solicitavam ajuda e para organizar a sala para a próxima turma.

Quando uma turma de $2^{\circ}$ período entrou, uma criança ficou sentada na direção onde estava a obra de Mondrian, Árvore Cinza. Depois que as professoras explicaram que eles eram livres para criar o que quisessem, mas que também podiam usar referências das obras expostas, ela prontamente sentenciou: "Eu quero pintar uma árvore como aquela ali!". As professoras se entreolharam e comentaram: "A gente não percebeu que era árvore e ele viu na hora!".

Figura 8 - A árvore amarela de David Guache sobre papel

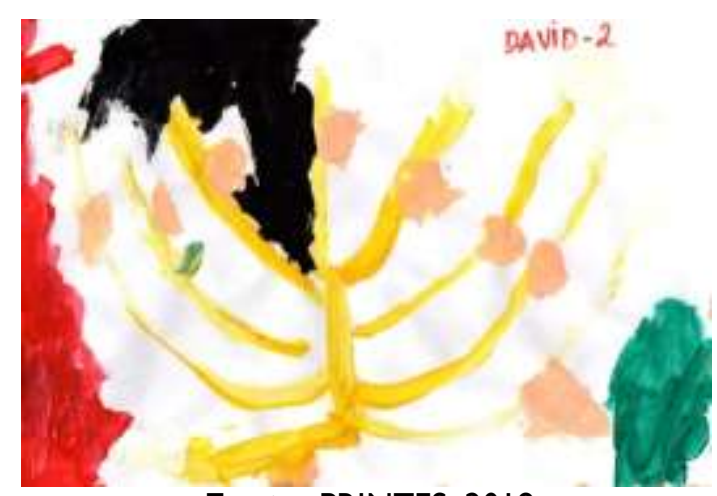

Fonte: PRINTES, 2018

Chamamos esse episódio para indagarmos sobre o que estamos possibilitando de acesso às crianças no campo das artes: Que experiências têm alimentado o seu ato criador? Trabalhamos nosso olhar para além de representações figurativas? Que imagens estão nas paredes dos CMEls? Conseguimos ir além daquelas veiculadas pela grande mídia, como personagens de filmes, desenhos animados, musicais e propagandas de brinquedos?

Oliveira (2014) tece uma discussão sobre os limites que a indústria cultural apresenta à criança, empobrecendo o olhar e a formação estética. Ela afirma que isso se dá porque os adultos não reconhecem a arte como um elemento necessário ao desenvolvimento da criança e, por isso, cerceiam seu acesso. Segundo lavelberg (1995, p. 4), precisamos organizar um ambiente propício ao 
desenvolvimento da expressão, porque "o sujeito vai construindo progressivamente suas teorias sobre o desenho a partir da interação com todas as produções que observa, incluindo as suas próprias".

Ampliar o repertório das crianças e trabalhar para que a leitura desse repertório não seja ingênua e superficial é um exercício a ser desenvolvido desde a educação infantil, em todas as formas de expressão humanas. E como a criança terá esse acesso? Somos nós os portadores dos signos, é nossa a responsabilidade de estreitar essa distância que existe entre o singular e o universal, criando, na particularidade da criança, condições de acesso e conhecimento (LUKÁCS, 1978). Para isso, nós, professores nas escolas da infância, precisamos alargar o nosso repertório. E como fazer isso se a nossa particularidade também foi/é embrutecida pelas necessidades desumanizadoras de um sistema em que o objeto só é nosso se o tivermos? (MARX, 2008).

A formação da sensibilidade estética tem estreita relação com a educação do olhar, do ouvir, do sentir, com a formação dos sentidos para acolher os encantamentos que o mundo e as coisas ainda causam nas crianças. A escola precisa ser o lugar onde os encontros acontecem e não o lugar onde os distanciamentos são impostos, como denunciava Malaguzzi:

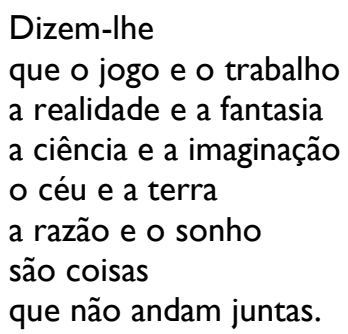

A formação da sensibilidade estética precisa ser uma preocupação da formação de professores. É um campo formativo que demanda leitura, discussão, fruição. Ir aos espaços onde há mostras, exibições. Experimentar as variadas manifestações artísticas que se espalham pela cidade. Conhecer artistas, suas obras, seu tempo histórico e cultura, conhecer artistas locais, dialogar com eles etc. Estreitar as relações entre a faculdade de educação e a faculdade de artes. Existem muitos caminhos para "promover e fomentar uma apropriação-fruição das obras que promova a consciência e permita o desenvolvimento da autoconsciência" (PEIXOTO, 2003, p. 47). É necessário criar as condições de acesso, mas é imprescindível

[...] criar necessidades e prazeres especificamente humanos, tais como: a acuidade perceptiva e a agudeza de sensibilidade, o exercício da capacidade de reflexão, de interpretação e de crítica, entre outros, pois que a arte é criação-produto específico do homem e só à sua humanização deve se destinar (PEIXOTO, 2003, p. 48).

Compreender o desenvolvimento do desenho sob a perspectiva da teoria Histórico-Cultural nos permitiu um salto qualitativo na discussão sobre o desenvolvimento da criança e de sua expressão. 
Os resultados alcançados pela pesquisa nos instigam a continuar explorando, a seguir com os questionamentos que nos trouxeram até aqui. $O$ acesso às variadas linguagens artísticas deve ser uma defesa dos professores da infância, a fim de garantir meios para que o desenho cultivado na criança seja exercitado diariamente. A imersão e o progressivo domínio da linguagem gráfica, em suas diversas formas de expressão, é prerrogativa legal das Diretrizes Curriculares Nacionais para a Educação Infantil. À criança, deveremos garantir o direito ao desenvolvimento dessa expressão, em uma escola que acolhe e instiga seu ser poético, que alarga seus padrões de referência e que a aproxima daquilo que de mais elevado a humanidade já produziu.

\section{Referências}

AUGUSTO, S.O. Ver depois de olhar: a formação do olhar do professor para o desenho da criança. São Paulo: Cortez, 2014.

BRASIL. Resolução no 5, de 17 de dezembro de 2009. Fixa as Diretrizes Curriculares Nacionais para a Educação Infantil. Disponível em: http://portal.mec.gov.br. Acesso em: 17 jan. 2021.

CUNHA, S.L. Brincar e aprender. v. I. São Paulo: PESC, 201 I.

DERDYK, E. Formas de pensar o desenho: desenvolvimento do grafismo infantil. Porto Alegre: Zouk, 2010.

ELKONIN, D. B. Sobre o problema da periodização do desenvolvimento psíquico na infância. In: LONGAREZZI, A.M; PUENTES, R. V (Orgs.). Ensino desenvolvimental: antologia. Trad. Ademir Damazio. Livro I. Uberlândia, MG: EDUFU, 2017.

FISCHER, E. A necessidade da arte. Trad. Leandro Konder. 5. ed. Rio de Janeiro: Zahar, 1976.

GOMBRICH, E. H. A história da arte. Trad. Álvaro Cabral. I6. ed. Rio de Janeiro: LTC, 2015.

GOMES, M. O. Grupos de pesquisa/formação: potencializando o desenvolvimento profissional de educadoras de crianças pequenas. In: PIMENTA, S. G; GHEDIN, E.; FRANCO, M. A. S. Pesquisa em Educação: alternativas investigativas com objetos complexos. São Paulo: Loyola, 2006.

IAVELBERG, R. O desenho cultivado da criança: prática e formação de educadores. 2. ed. Porto Alegre: Zouk, 2013.

IAVELBERG, R. O desenho cultivado da criança. In: CAVALCANTI, Z. Arte na sala de aula. Porto Alegre: Artes Médicas, 1995.

KONDER, L. Os marxistas e a arte: breve estudo histórico-crítico de algumas tendências da estética marxista. 2. ed. São Paulo: Expressão Popular, 2013.

LEITE, M. I.; OSTETTO, L. E. Formação de professores: o convite da arte. In: OSTETTO, L. E.; LEITE, M. I. Arte, infância e formação de professores: autoria e transgressão. 7. ed. Campinas, SP: Papirus, 2012. 
LONGAREZI, A. M.; SILVA, J. L. Pesquisa-formação: um olhar para a sua constituição conceitual e política. Contrapontos. vol. 13, n. 3, p. 214-225, set./dez. 2013. Disponível em: https://siaiap32.univali.br/seer/index.php/rc/article/view/4390. Acesso em: 20 set. 2016.

LUKÁCS. G. Introdução a uma estética marxista: sobre a categoria da particularidade. Trad. Carlos Nelson Coutinho e Leandro Konder. Rio de Janeiro: Civilização Brasileira, 1978.

MARTINS, M. C; PICOSQUE, G; GUERRA, M. T. Didática do ensino de arte: a língua do mundo, poetizar, fruir e conhecer arte. São Paulo: FTD, 1998.

MARX, K. Manuscritos econômicos e filosóficos. Trad. Jesus Ranieri. 2. ed. São Paulo: Boitempo, 2008.

MELLO, S. A. Infância e humanização: algumas considerações na perspectiva histórico-cultural. Perspectiva, Florianópolis, v. 25, n. I, p. 83-104, jan./jun. 2007. Disponível em: https://periodicos.ufsc.br/index.php/perspectiva/article/view/1630. Acesso em: 25 jan. 2017.

OLIVEIRA, K. A. S. Possibilidades da experiência estética na educação da infância: uma proposta com leituras de imagens. Curitiba: Appris, 2014.

OSTETTO, L. E. Educação infantil e arte: sentidos e práticas possíveis. Caderno de Formação 6: Formação de professores - educação infantil - princípios e fundamentos. Acervo digital Unesp, v. 3, p. 27-39, mar. 20I I. Disponível em: http://www.acervodigital.unesp.br/handle/123456789/320. Acesso em: 22 jan. 2017.

PEIXOTO, M. I. H. Arte e grande público: a distância a ser extinta. Campinas, SP: Autores Associados, 2003.

PERRELLI, M. A. S. et. al. Percursos de um grupo de pesquisa-formação: tensões e (re)construções. Revista Brasileira de Estudos Pedagógicos. Brasília, v. 94, n. 236, p. 275-298, jan./abr. 2013. Disponível em: http://rbep.inep.gov.br/ojs3/index.php/rbep/article/view/3541. Acesso em: 10 jan 2017.

PILLAR, A. D. Leitura e Releitura. In: PILLAR, A. D. (Org.). A educação do olhar no ensino das artes. 8. ed. Porto Alegre: Mediação, 2014.

PINTO, A. V. O significado ideológico da pesquisa científica e a formação do pesquisador. In: PINTO, A. V. Ciência e existência. Rio de Janeiro: Paz e Terra, 1969.

PRINTES. Jocicleia Souza. O desenho na educação infantil: perspectivas de formação de professores a partir da teoria Histórico Cultural. 2018. 287f. Tese (Doutorado em Educação). Universidade Federal do Amazonas, Manaus, 2018.

SILVA, M. C. A constituição social do desenho da criança. Campinas, SP: Mercado das Letras, 2002.

TSUHAKO, Y. N. O desenho como expressão da criança. In: COSTA, S. A; MELLO, S. A (Org.). Teoria Histórico-Cultural na Educação Infantil: conversando com professoras e professores. Curitiba: CRV, 2017.

VIGOTSKI, L.S. Imaginação e criação na infância: ensaio psicológico. Trad. Zoia Prestes. São Paulo: Ática, 2009.

Olhar de professor, Ponta Grossa, v. 24, p. I-24, e-I7664.07I, 202 I.

Disponível em <https://revistas2.uepg.br/index.php/olhardeprofessor> 
VIGOTSKI, L.S. Psicologia da arte. Trad. Paulo Bezerra. São Paulo: Martins Fontes. 1999.

VIGOTSKI, L. S. Quarta aula: a questão do meio na pedologia. Trad. Marcia Pileggi Vinha e Max Welcman. Psicologia USP, São Paulo, v. 2I, n. 4, p. 68I-70I, 20I0. Disponível em: https://www.revistas.usp.br/psicousp/article/view/42022. Acesso em I0 dez. 2016.

VYGOTSKI, L.S.; LURIA, A. R. El instrumento y el signo en el desarrollo del niño. Trad. Pablo del Río. Madrid: Fundación Infancia y Aprendizaje, 2007.

ZAPORÓZHETS, A. Importancia de los períodos iniciales de la vida en la formación de la personalidad infantil. In: DAVIDOV, V; SHUARE, M. (Orgs.) La psicología evolutiva y pedagógica en la URSS. Moscou: Editorial Progresso, 1987.

Recebido em: 17 de março de 2021.

Versão corrigida recebida em: 20 de abril de 2021.

Aceito em: 14 de junho de 2021 .

Publicado online em: 02 de julho de 2021 . 